\title{
EL GÉNERO EN EL DISCURSO: "LOS NIÑOS ACTÚAN, LAS NIÑAS EXISTEN" ENTREVISTA A CARMEN ROSA CALDAS-COULTHARD"
}

\author{
Oscar Iván Londoño Zapata*^ \\ Universidad del Tolima \\ Ibagué, Tolima, Colombia
}

Múltiples campos de saber como la antropología, la sociología, la filosofía, la comunicación y el periodismo, la psicología, entre otros, han llevado a cabo estudios sobre la identidad de género a través de variadas perspectivas o metodologías (etnografías, experimentos de laboratorio, encuestas, entrevistas, exégesis filosóficas y estudios del habla y la escritura). De tal forma, las ciencias del lenguaje también se han interesado por el estudio de la compleja relación entre discurso, género y sociedad. No obstante, fue en la segunda mitad del siglo XX cuando el género empezó a cobrar relevancia para campos como los Estudios del Discurso (ED), puesto perspectivas como la lingüística textual, la semántica y la psicología del procesamiento de textos, entre otras, no habían volteado su mirada analítica hacia este fenómeno.

Lo anterior se produjo gracias al desarrollo de movimientos sociales y políticos que iniciaron profundas reflexiones acerca del papel de la mujer en las sociedades patriarcales. De esta manera, el denominado Movimiento de las Mujeres (Women's Movement) gestó un notable interés sobre las relaciones entre género y lenguaje al interior de las comunidades académicas. Es así como desde la década del setenta del mismo siglo "el estudio del género y el discurso alcanzó reconocimiento no sólo como un campo de investigación maduro sino también como uno que avanza a pasos agigantados" (WEST et al., 2005, p. 179).

En este sentido, los Estudios del Discurso (ED) y los Estudios Críticos del Discurso (ECD) han aportado múltiples perspectivas de abordaje, conducentes a analizar la manera como el género se configura en el discurso, pues "como muchos investigadores feministas mostraron, lo que consideramos comportamiento femenino o masculino no está regido por la biología sino que se construye socialmente, y un ámbito fundamental en el que se construye el género es el uso del lenguaje" (WEST et al., 2005, p. 180). De tal forma, la construcción social del género se concibe como una práctica que no es neutral y que está directamente vinculada a las relaciones de poder institucionalizadas dentro de las sociedades. De ahí el interés de los Estudios Críticos del Discurso (ECD) en el análisis de la construcción de género en múltiples discursos

\footnotetext{
* Esta entrevista fue realizada en el año 2012 a través de comunicación electrónica escrita.

** Licenciado en Lengua Castellana y Magíster en Educación de la Facultad de Ciencias de la Educación de la Universidad del Tolima, Colombia. Profesor Asistente del Departamento de Estudios Interdisciplinarios. Instituto de Educación a Distancia (IDEAD). Email: oilondonoz@ut.edu.co
} 
institucionales: medios de comunicación, publicidad, discursos políticos, educativos, académicos, entre otros.

América Latina no ha sido una región ajena al desarrollo de los estudios de género y discurso. Una de las autoras que se ha interesado por este campo de abordaje del lenguaje es Carmen Rosa Caldas-Coulthard quien, desde el Brasil e Inglaterra, ha aportado de manera activa en el desarrollo de los Estudios del Discurso tanto en Europa como en América Latina. Carmen Rosa fue una de las primeras investigadoras que introdujo el área del Análisis Crítico del Discurso (ACD) o los Estudios Críticos del Discurso (ECD) en Brasil en la década de los años ochenta del siglo XX. Su enfoque en estos primeros estudios se orientó hacia la manera como las relaciones de género se representaban en el discurso, interés investigativo que ha desarrollado ampliamente en Europa durante varias décadas.

Para Caldas-Coulthard:

\begin{abstract}
Na década de 80, lingüistas nos EEUU, França e Inglaterra, começaram a tentar resgatar os códigos lingüísticos através da mudança - este seria o movimento reformista. Experimentos com formas alternativas (formas lexicais - chairperson, o uso dos pronomes -s/he, they para indivíduos, etc...) foram lançados. Foi também nesta fase que mulheres lingüistas, como Dale Spender (1980), questionaram conceitos gramaticais como masculinos. O famoso lingüista Otto Jespersen (1922), por exemplo, dizia que as mulheres preferiam expressões refinadas, eufemísticas e hiperbólicas e que os homens usavam mais gírias, eram mais criativos, e falavam menos que as mulheres. Afirmações deste tipo construíram estereótipos difíceis de serem desconstruídos (2007, p. 234).
\end{abstract}

Esta distinción comentada por Caldas-Coulthard ha hecho que se (re)construyan estereotipos cristalizados sobre las mujeres y sus expresiones discursivas. Es por ello que preguntas como: ¿Qué relación se establece entre género y discurso? ¿Qué papel cumple el lenguaje en la construcción de la identidad de género? ¿Qué aportes han realizado los Estudios del Discurso y los Estudios Críticos del Discurso en el análisis de la relación género-discurso? ¿De qué manera se concibe el género en el campo de los Estudios del Discurso? ¿Cómo se usa el discurso para discriminar y segregar a las mujeres? ¿Qué representaciones se construyen sobre las mujeres en los discursos académicos, periodísticos, educativos, humorísticos, políticos, religiosos, mediáticos...? ¿Qué posición tiene la mujer en la comunidad académica y científica? ¿Cómo contribuyen las prácticas sociales sexistas en la construcción de discursos patriarcales dominantes?, son, entre otros, algunos de los interrogantes que permiten abordar la relación género-discurso para develar las relaciones de poder dominantes no solo constituidas en prácticas sociales, sino además en prácticas discursivas.

En esta entrevista, Carmen Rosa Caldas-Coulthard, docente e investigadora de la Universidad de Birmingham, da a conocer sus principales aportes al desarrollo de los Estudios del Discurso y, de manera particular, a los estudios de género y discurso. 


\section{LOS ESTUDIOS DEL DISCURSO EN AMÉRICA LATINA: UNA MIRADA AL BRASIL}

Oscar Iván Londoño Zapata (OILZ): Permitame iniciar esta entrevista preguntándole: ¿de qué manera evalúa el impacto de la Asociación Latinoamericana de Estudios del Discurso (ALED) en el desarrollo de este campo de abordaje del discurso en sociedad?

Carmen Rosa Caldas-Coulthard (CRC-C): Desde seu primeiro congresso encabeçado por Adriana Bolívar, minha colega de doutorado na Universidade de Birmingham na década de 80, a ALED tem contribuído sensivelmente para o desenvolvimento dos estudos de Análise de Discurso na América Latina. Seus congressos são muito concorridos, demonstrando o interesse de diferentes pesquisadores/as latinoamericanos/as pela área. A ALED tem trazido para a América Latina grandes analistas de discurso, dando a oportunidade aos/às alunos/as que não têm contato direto com a pesquisa europeia e norte-americana de estar em contato com essas teorias. A ALED é, portanto, de suprema importância para os estudos discursivos.

OILZ: ¿Cómo ha sido el desarrollo de los Estudios Críticos del Discurso (ECD) en Brasil?

CRC-C: Os estudos críticos discursivos (ECD) têm se desenvolvido significativamente no Brasil desde a década de 90. Centros específicos de estudos críticos são a Universidade Federal de Minas Gerais, a Universidade Federal de Santa Catarina (UFSC), onde eu mesma introduzi o aparato teórico, quando terminei minha tese de doutorado na Universidade de Birmingham e voltei a trabalhar na UFSC, no final da década de 80. Posso citar, ainda, a Universidade de Brasília e a Universidade de São Paulo como centros de excelência nos estudos críticos.

OILZ: ¿Qué problemas han sido privilegiados en ED y ECD?

CRC-C: Vários problemas têm sido abordados pelos estudos brasileiros, como a discriminação da imprensa em relação à mulher, a exclusão de atores sociais em discursos institucionais, as questões de raça, assim como o exame de interações e a questão do poder em ambientes políticos.

OILZ: ¿Cuáles son las perspectivas torico-metodológicas más empleadas por los analistas del discurso en Brasil?

CRC-C: As perspectivas teóricas mais usadas por pesquisadores/as são as de origem anglo-saxônica e francesa.

OILZ: ¿Qué impacto han tenido las investigaciones y publicaciones sobre los Estudios Críticos del Discurso (ECD) brasileras en la comunidad académica nacional e internacional?

CRC-C: Tenho a impressão de que os Estudos Críticos do Discurso (ECD), como área de estudo, mudaram radicalmente a maneira como pesquisadores/as enfocam seus 
objetos de pesquisa. Não se olha mais para um texto simplesmente para descrevê-lo, mas primordialmente para se entender como esse texto é inserido em seu contexto social e seus efeitos na prática discursiva. $\mathrm{O}$ impacto dos resultados atingidos é bastante significativo, pois muita coisa já mudou em termos de representação social. Infelizmente, e isto é um problema para toda a América Latina, vários estudos interessantes produzidos em Português não atingem a comunidade internacional. Esse problema tem sido discutido há muitos anos. É muito importante, portanto, que nossos/as pesquisadores/as tenham acesso à língua inglesa e que publiquem seus estudos em periódicos internacionais.

$\mathrm{O} / \mathrm{A}$ pesquisador/a tem a liberdade de usar a metodologia que lhe for mais apropriada e assim construir seu próprio construto epistêmico. É óbvio que as ideias que iniciaram este tipo de investigação são provenientes de grande centros europeus. Mas acho que podemos adaptá-las para nosso próprio uso, e temos também a capacidade de desenvolver outras teorias relevantes para a nossa situação social.

OILZ: ¿De qué manera fueron recibidos los Estudios Críticos del Discurso (ECD) en su pais?

CRC-C: Sem dúvida, a resistência foi enorme, principalmente nas década de 80/90. Hoje em dia, os estudos críticos estão bem aceitos e estabilizados. Lembro-me perfeitamente de uma ocasião, na década de 80 , quando se começava a introduzir a questão de gênero nos estudos discursivos, de um problema criado numa apresentação minha em um grande congresso. Minha palestra tratava de como a linguagem reforçava preconceitos de sexo e de raça, e eu me referia ao uso do masculino genérico como uma regra que deveria ser mudada, já que as mulheres não estavam presentes linguisticamente em textos. Uma das famosas pesquisadoras de gramática portuguesa interpelou-me, dizendo 'mas a gramática diz que esta é a regra a ser seguida'. Minha resposta foi 'mas quem escreve as gramáticas?'. A resistência, principalmente sobre as questões de gênero, ainda é sentida em muitos ambientes acadêmicos, mas a situação, a meu ver, começa a ser mudada.

OILZ: ¿Cuáles fueron los primeros temas abordados por usted desde los Estudios Críticos del Discurso (ECD)?

CRC-C: Vindo diretamente da Inglaterra, onde estudei com grandes linguistas como Norman Fairclough e outros da Universidade de Birmingham, meus interesses maiores sempre foram a questão de gênero e os modos como atores sociais são representados. Minha primeira grande investigação, desenvolvida com um grupo de alunas de doutorado e mestrado na Universidade Federal de Santa Catarina (UFSC), em Florianópolis, na década de 80 , foi um estudo bastante abrangente sobre revistas femininas. Desse estudo resultaram muitos trabalhos e, hoje em dia, considero nossa pesquisa realmente pioneira. As pesquisadoras envolvidas nesse trabalho hoje são acadêmicas reconhecidas no Brasil, como Viviane Heberle, Ana Cristina Ostermann e Débora Figueiredo, todas trabalhando atualmente com discurso crítico. 
OILZ: La educación es uno de los campos más estudiados por los analistas del discurso. ¿De qué forma contribuyen los ECD en el desarrollo de mejores procesos de formación escolar?

CRC-C: Acho que os Estudos Críticos do Discurso (ECD) são fundamentais para a educação em geral. Precisamos formar sujeitos cientes e críticos, principalmente na América Latina, onde a desigualdade social é tão profunda. Precisamos, também, atuar na formação de professores/as cientes de seu papel de reformadores/as sociais. A escola, apesar de Paulo Freire, ainda não é crítica o suficiente. Nosso trabalho como pesquisadores/as é extremamente importante para a divulgação de uma consciência crítica. Temos ainda muito a fazer.

OILZ: Uno de los mayores exponentes de la perspectiva educativa crítica en América Latina es Paulo Freire. Desde hace algunos años sus propuestas han sido incorporadas en las investigaciones de los ECD. ¿Es posible consolidar las ideas de Freire sobre la educación en Latinoamérica?

CRC-C: Não só possível, como essencial. O trabalho do grande Paulo Freire deveria ser a base para uma educação crítica e construtiva. Infelizmente, acho que as ideias freirianas ainda não atingiram todos os campos de educação no Brasil. Um de nossos trabalhos como analistas de discurso seria o de divulgar ainda mais o trabalho de Paulo Freire em toda a América Latina. Talvez um tópico para um próximo encontro da ALED?

OILZ: ¿Cuál es su posición acerca de la introducción de los Estudios del Discurso (ED) y los Estudios Críticos del Discurso (ECD) en la secundaria?

CRC-C: Como disse antes, precisamos urgentemente divulgar nossos trabalhos e resultados na escola primária e secundária. Se começarmos mais cedo, teremos uma sociedade mais consciente e igualitária. No momento, no entanto, os estudos críticos somente começam a influenciar a formação de professores/as no nível universitário. Muito ainda precisa ser feito para que alunos/as em formação secundária tenham uma educação emancipadora.

\section{GÉNERO Y DISCURSO: ENTRE EL ACTION MAN Y LA BARBIE}

OILZ: Junto con Malcolm Coulthard editó en 1996 el libro Text and Practices: Readings in Critical Discourse Analysis. ¿Qué impacto tuvo en la comunidad académica?

CRC-C: Na verdade, nosso livro Text and Practices foi o primeiro livro a nomear a área 'Critical Discourse Analysis', e isso aconteceu na década de 90. Este livro é ainda citado por muitos/as investigadores/as e foi um marco inicial nos estudos discursivos. Sinto-me, obviamente, muito orgulhosa desse trabalho. Vários problemas foram 
abordados nesse livro, problemas que até então não eram estudados, como discriminação na mídia, interações de poder, a questão da representação da mulher e de pessoas idosas, além de formas teóricas de se aplicar este novo enfoque que hoje em dia é tão citado por todos/as.

OILZ: En esta compilación publicó el capitulo 'Women who pay for sex. And enjoy it'. Transgression versus morality in women's magazines. ¿Cómo se expresa dicha tensión en las revistas femeninas?

CRC-C: Na sociedade de consumo em que vivemos, mulheres e seus corpos são produtos usados para serem vendidos. Sexo e sexualidade são tópicos recorrentes em revistas femininas, usados como estratégia de marketing. No entanto, a maioria dessas revistas, apesar de usar tópicos 'transgressivos' (infidelidade, sexualidade 'anormal', entre outros) para vender seu produto, ainda reproduz discursos moralistas, e as relações de poder representadas nessas publicações são altamente diferenciadas. Assim, as ideologias tradicionais, embora encobertas por tópicos 'modernos', continuam a reproduzir assimetrias sociais através de seus discursos.

OILZ: En el 2002 fue publicado el libro Gender Identity and Discourse Analysis, coordinado por Lia Litosseliti y Jane Sunderland. La publicación agrupa textos de reconocidos analistas del discurso (Michelle M. Lazar, Carmen Rosa CaldasCoulthard, Theo van Leeuwen, entre otros). En co-autoria con Theo van Leeuwen presentó el capitulo Stunning, shimmering, iridescent: Toys as the representation of gendered social actors. ¿Cuáles son los principales fundamentos de este trabajo?

CRC-C: Fizemos uma grande investigação sobre a questão de Toys (brinquedos, em português, e juguetes, em espanhol) e Comunicação, pois nossa hipótese era a de que brinquedos, como todo o objeto semiótico multimodal, comunica significados diversos e muito interessantes. Olhamos para vários brinquedos, como Teddy Bears, Baby Toys, Dolls, entre outros. Ficamos maravilhados ao descobrir que brinquedos, na verdade, são um microcosmo da sociedade, que representam e carregam em si todas as ideologias inerentes a essa sociedade.

OILZ: ¿Qué relación se establece entre los juguetes y las representaciones sociales de género?

CRC-C: No trabalho citado acima, nos interessamos em analisar como as questões de gênero estão presentes no mundo infantil e como assimetrias sociais são representadas nos objetos semióticos. O Action Man, por exemplo, move todas as suas articulações, e a criança interage com esse objeto de uma forma plena, pois a representação dos corpos masculinos é bastante realista. A Barbie Doll, contrastivamente, apresenta uma representação minimalista do corpo feminino. Seu corpo não se move, não fica em pé sem ser apoiada por um salto alto (high heels). A Barbie é a clássica representante do gênero feminino - ela existe, enquanto o Action Man age. 
OILZ: ¿Qué impacto podrían tener estas investigaciones en la formación de niños y niñas?

CRC-C: Essas descobertas iluminadoras são essenciais para uma educação crítica. As escolas precisam saber, e naturalmente desconstruir, as ideologias assimétricas embutidas em brinquedos.

\section{PUBLICIDAD Y DISCURSO}

OILZ: ¿Cómo contribuir en la superación del fenómeno de alienación publicitaria del consumidor?

CRC-C: A mídia é, talvez, a instituição mais poderosa, e deve ser analisada constantemente. Nosso papel como analistas críticos/as é o de desconstruir seu posicionamento assimétrico em todos os sentidos. Isso não é uma tarefa fácil. Não temos acesso aos seus produtores (é muito difícil, por exemplo, interagir com editores e escritores), e nossa crítica não atinge esses produtores sociais. Mas devemos continuar tentando, e nossas análises devem demonstrar a validade de nossas asserções. Só através de 'consciouness raising' é que podemos produzir mudança. $\mathrm{O}$ consumidor precisa saber de seu papel como consumidor. A educação, portanto, é o único caminho, a meu ver.

OILZ: En el 2008 publicó el artículo Body branded: Multimodal identities in tourism advertising. Desde una perspectiva semiótico-discursiva y social investigó acerca de la publicidad de turismo. ¿Qué identidades se construyen en el discurso de la publicidad sobre el turismo?

CRC-C: Muitas identidades são construídas no discurso do Turismo - a viajante, a expectadora, a consumidora de produtos, as pessoas locais que ajudam o turismo, etc. Esse mundo é bastante interessante para uma reflexão crítica.

OILZ: ¿De qué manera es utilizada la representación del cuerpo humano en la publicidad?

CRC-C: O discurso da publicidade usa o corpo humano com um produto essencial para vender outros produtos. Nesse trabalho, meu interesse foi desvendar como há assimetria na representação de corpos de homens e mulheres. Como no mundo dos brinquedos, as mulheres no turismo simplesmente existem, e os homens fazem ou agem. Os corpos femininos transmitem significados sexuais para persuadir um/a viajante a comprar uma viagem. Isso é muito problemático, tendo em vista a questão do abuso sexual de crianças, principalmente no Brasil, e a questão do turismo sexual. Muito ainda precisa ser estudado nesse discurso institucional. Eu apenas 'toquei' em sérios problemas que precisam ser analisados e discutidos. 
OILZ: En el 2008 editó, junto con Rick Iedema, el libro Identity Trouble: Critical Discourse and Contested Identities. ¿Qué contribuciones realiza el texto en la comprensión de la construcción de identidades?

CRC-C: Esse livro nasceu de uma conferência em Aallborg, na Dinamarca, sobre questões identitárias. Os trabalhos apresentados durante esse encontro (muitos deles publicados no livro) abordavam o problema de pessoas deslocadas de seu meio ambiente, ou problemáticas em relação ao seu posicionamento no mundo. Resolvemos, então, produzir o livro, para que nossos trabalhos fossem mais divulgados. E, realmente, no mundo global onde vivemos, todos somos 'mongrel', como eu chamei os brasileiros que vivem em Londres, adaptando-se a um mundo estrangeiro da maneira que podem.

Os diversos trabalhos no livro abordam as questões identitárias sobre vários enfoques - linguísticos, semióticos e discursivos. Os resultados são fascinantes, e há um consenso de que as identidades são realmente construídas em discurso.

OILZ: Em que reside seu interesse em investigar a construção discursiva de identidades?

CRC-C: Principalmente nas questões de gênero e, atualmente, na questão do envelhecimento, meu projeto de investigação atual.

OILZ: ¿Cómo ha sido el desarrollo de las investigaciones en género y discurso desde los ECD?

CRC-C: Esta é, para mim, a linha principal de minhas investigações, já que considero as representações de gênero inerentes a todos os tipos de discurso. Desde a década de 70 que as linguistas feministas têm se debruçado sobre como a linguagem e os sistemas semióticos dividem o mundo assimetricamente entre homens e mulheres. Muito já foi feito; em inglês, por exemplo, a referência genérica não é mais masculina não se fala de 'fire-man', mas somente de 'fire-worker'-, e as mulheres estão muito mais presentes em textos. No Brasil, no entanto, por causa do gênero gramatical, as mulheres são exaustivamente excluídas de textos. Note, por exemplo, que faço questão, em meu texto, de me referir sempre aos dois sexos quando uso a referência genérica (os/as alunos/as), mas esse é um trabalho complicado e muitas vezes não entendido pela maioria das pessoas. Como já disse, muito já foi feito na América Latina, mas ainda há muito a ser feito.

OILZ: En 1999 organizó con Luisa Martín Rojo un número especial sobre revistas para mujeres en la Revista Iberoamericana de Discurso y Sociedad.

CRC-C: A experiência de trabalhar com a grande investigadora Luisa Martín Rojo foi muito gratificante, principalmente por divulgarmos tantos trabalhos interessantes produzidos por investigadoras europeias e latinoamericanas. Esse trabalho demonstrou o quanto tem sido feito nos estudos críticos do discurso no mundo latino. Vários 
problemas foram abordados, mas o mais importante é que estamos investigando essas questões cruciais na sociedade moderna. Não somente a mulher é excluída de práticas sociais, mas também minorias, e a ideologia patriarcal é ainda dominante em muitos discursos institucionais e pessoais.

OILZ: ¿De qué manera evalúa el papel desempeñado por las mujeres en los Estudios Críticos del Discurso (ECD)?

CRC-C: Como disse acima, muito já foi mudado devido ao trabalho intenso de feministas atuando em várias áreas do saber. Mulheres atualmente também atuam em posições de poder. O discurso crítico sem dúvida contribuiu e tem contribuído para essa mudança e transformação. Mas também acho que essa aparente mudança ainda é estética. Por exemplo, um novo governo inglês foi recentemente eleito, e nenhuma mulher faz parte do novo ministério. Quem são os grandes cirurgiões, os grandes legistas? Poucas mulheres podem ser citadas nessas posições. A inclusão da mulher é, portanto, ainda, incipiente.

OILZ: ¿Cómo lograr que las comunidades marginales se empoderen y generen transformaciones reales de las prácticas sociales y discursivas dominantes?

CRC-C: Minha posição é que precisamos continuar lutando para um mundo melhor onde todas as pessoas, não importando seu gênero, orientação social ou cor de sua pele, tenham os mesmos direitos. Como analistas críticas de discurso, por meio de nosso trabalho, temos de continuar denunciando práticas abusivas e discriminatórias. Mas, como você mesmo diz, este é trabalho complexo e difícil. Só através da educação é que se mudam as relações de poder.

OILZ: ¿Cómo ha sido la experiencia de trabajar en Inglaterra?

CRC-C: Trabalho na Inglaterra há quase 17 anos, quando deixei a Universidade Federal de Santa Catarina para trabalhar na University of Birmingham. Minha experiência inglesa é muito positiva em todos os sentidos. É fácil se ter acesso aos trabalhos publicados na Europa e nos Estados Unidos, os/as colegas são pesquisadores/as de primeira linha e os recursos para o trabalho acadêmico são facilmente disponíveis. Assim, é um prazer trabalhar na Europa.

OILZ: ¿Cuáles son las principales perspectivas teóricas y metodológicas empleadas por los analistas del discurso en Inglaterra?

CRC-C: Várias são as linhas de pesquisa, dependendo dos centros de investigação. A multimodalidade é uma grande área de novidade, assim como os estudos de imigração, discursos políticos e institucionais. 
OILZ: Finalmente, ¿cómo formular una investigación a partir de una perspectiva critica discursiva?

CRC-C: Ensino na Universidade de Birmingham um curso para o Mestrado em Critical Discourse Analysis, e sempre digo aos meus/minhas alunos/as que devem investigar tópicos que lhes sejam relevantes e motivadores. É muito importante que principiantes tenham um conhecimento básico de formas de comunicação, principalmente a linguagem, que leiam bastante o que já foi publicado e que tentem realmente 'investigar' um problema coletando seus dados e os analisando sob um enfoque teórico. A investigação dever sempre ser iniciada com esse problema. Há, obviamente, muitas formas de se formular uma investigação, e isso vai depender do interesse pessoal do/a investigadora/a. O importante, no entanto, é o conhecimento do que já foi feito através de leitura e discussão com professores.

OILZ: Reciba mi agradecimento por haber aceptado esta enrevista.

CRC-C: Agradeço também pelo convite e pela oportunidade de conversarmos sobre os estudos discursivos, que, a meu ver, são tão importantes para o desenvolvimento da educação e para a conscientização social. Espero que seus alunos/as e colegas desenvolvam muitas pesquisas nessa área.

\section{REFERÊNCIAS}

CALDAS-COULTHARD, C. R. 'Women who pay for sex. And enjoy it'. Transgression versus morality in women's magazines. Texts and Practices: Readings in Critical Discourse Analysis. London: Routledge, 1996. p. 248-268. 230-24, 2007.

Caro Colega: Exclusão lingüística e invisibilidade. Revista Discurso \& Sociedad, v. 1, n. 2, p.

Body branded: multimodal identities in tourism advertising. Jounal of Language and Politics-

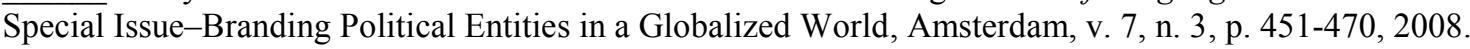
CALDAS-COULTHARD, C. R.; COULTHARD, M. Texts and Practices: Readings in Critical Discourse Analysis. London: Routledge, 1996.

CALDAS-COULTHARD, C. R.; VAN LEEUWEN, T. Stunning, shimmering, iridescent: toys as the representation of gendered social actors. In: Gender Identity and Discourse Analysis. Amsterdam: John Benjamin's, 2002. p. 91-110.

CALDAS-COULTHARD, C. R.; IEDEMA, R. (Eds.). Identity Trouble: Critical Discourse and Contested Identities. London: Palgrave, 2007.

WEST, C, LAZAR, M. M.; KRAMARAE, C. El género en el discurso. In: van DIJK, T. (Comp.). El discurso como interacción social. Estudios sobre el discurso II. Una introducción multidisciplinaria. Barcelona: Gedisa, 2005. p. 179-212.

Recebido em: 30/03/14. Aprovado em: 20/04/14. 